\title{
LA CORRUPCIÓN DE LA SOCIEDAD O LA LUCHA DEL VICIO CONTRA LA VIRTUD: LA MODE, CONTE (1807) DE BOUFFLERS ${ }^{1}$
}

\author{
Antonio José de Vicente-Yagüe Jara \\ Universidad de Murcia
}

\begin{abstract}
RESUMEN: En 1807, Boufflers publicó La Mode en el Mercure de France, en forma de folletín. La Mode es, por un lado, un cuento moral que se propone denunciar las fechorías de la moda, que corrompe y tiraniza a los hombres, y, por otro lado, un cuento edificante que demuestra que la virtud puede triunfar en cualquier parte. Este relato describe la corrupción que existe en los círculos mundanos de la alta sociedad parisina y que hace imposible toda forma de felicidad a los individuos buenos, sencillos y honrados.
\end{abstract}

PALABRAS CLAVE: Boufflers, cuento, moral, moda, corrupción, sociedad.

\section{LA CORRUPTION DE LA SOCIÉTÉ OU LA LUTTE DU VICE CONTRE LA VERTU: LA MODE, CONTE (1807) DE BOUFFLERS}

\begin{abstract}
RÉSUMÉ: En 1807, Boufflers fit publier La Mode dans le Mercure de France, sous forme de feuilleton. La Mode est, d'une part, un conte moral qui se propose de dénoncer les méfaits de la mode qui corrompt et tyrannise les hommes, et, d'autre part, un conte édifiant qui démontre que la vertu peut triompher partout. Il décrit la corruption qui existe dans les cercles mondains de la haute société parisienne et qui rend toute forme de bonheur impossible aux individus bons, simples et honnêtes.
\end{abstract}

MOTS CLÉS: Boufflers, conte, morale, mode, corruption, société.

1. Este trabajo se enmarca en los proyectos de investigación El relato corto francés del siglo XIX (FFI2010-19285, del Plan Nacional de I+D del Ministerio de Ciencia e Innovación) y Formas narrativas breves entre dos siglos. Estudio, recepción y traducción (11890/PHCS/09, financiado con cargo al Programa de generación de conocimiento científico de excelencia de la Fundación Séneca, Agencia de Ciencia y Tecnología de la Región de Murcia). 


\section{Introducción}

A principios del siglo XIX, cuarenta y seis años después de La Reine de Golconde (1761), relato libertino escrito por el entonces joven seminarista, Boufflers retomó su producción literaria y volvió al cuento, publicando, en el Mercure de France, otros dos cuentos en forma de folletín, La Mode y L'Heureux accident, ambos en 1807. Durante estos años, había hecho carrera militar, había servido como gobernador de Senegal (Vicente-Yagüe, 2012b: 154) y había pasado casi diez años en el exilio escribiendo obras de carácter teórico como Discours sur la vertu (1797) y Discours sur la littérature (1798); un año más tarde escribiría Le Libre arbitre (1808) (Vicente-Yagüe, 2008: 235).

Encontramos fuentes que nos aseguran, sin embargo, que, después de La Reine de Golconde (1761) y antes de la aparición de La Mode y L'Heureux accident (1807), Boufflers escribió otros cuentos. Pierre de Croze señala que, en los papeles de Elzéar de Sabran², había encontrado una nouvelle escrita por Boufflers titulada Ogive et Gullistan. Es la historia de una virgen púdica que se transforma en caballero para salvar la vida del rey Alfred, al que ama. Croze la califica de infantil y concluye que su autor "voulant réagir [...] a dépassé la mesure, il est devenu trop vertueux" (Croze, 1894: 90).

Por otro lado, Alex Sokalski comenta, en la introducción a su edición de los Contes de Boufflers: "Il y a même des critiques qui lui attribuent la parenté d'un roman en seize contes intitulé L'Exemple et les passions publié en 1785" (Sokalski, 1995: 93). Sokalski señala la existencia de una edición de 1785 y otra de 1786 , ambas con el título de L'Exemple et les passions, ou Aventures d'un jeune homme de qualité, ediciones en las que no aparece el nombre del autor, sino el epígrafe "Par M. de M......". Nicole Vaget Grangeat cita, en Le chevalier de Boufflers et son temps: étude d'un échec, a Adrien Sée, el cual, en su artículo "Bouffllers moraliste", publicado en 1900 en el Bulletin du Bibliophile et du Bibliothécaire, hablaba de la existencia de una obra aparecida en 1787 con el título de Anecdotes amoureuses d'un jeune homme de condition, ou L'Exemple et les passions, divisé en 16 contes (Vaget, 1976: 157). Sokalski duda de que Boufflers sea el autor de esta obra: "surtout ayant lu le roman et l'ayant trouvé vraiment très loin du brillant du style de Boufflers. Il est vrai que deux des personnages ont des noms que l'on retrouverait plus tard dans La Mode, Félix et Herminie" (Sokalski, 1995: 93). Es

2. Es el hijo de Éléonore de Sabran, viuda de Joseph de Sabran-Grammont, conde de Grammont y de Baudinard, que, en 1797, se casó con el caballero de Boufflers tras una relación de veinte años. 
sorprendente que no podamos encontrar ninguna alusión relativa a su composición o a su publicación en su correspondencia, que fue particularmente abundante en ese preciso momento ya que se encontraba en Senegal. Es igualmente curioso que ni Maugras, ni Croze-Lemercier, ni Uzanne, ni ninguno de sus biógrafos haya hablado nunca de estos cuentos. Sin embargo, existe, en la Bibliothèque Municipale de Lyon, una edición de dicha obra con el título de Anecdotes amoureuses d'un jeune homme de condition, ou L'Exemple et les passions, divisé en 16 contes $^{3}$ (el mismo título indicado por Sée y Vaget Grangeat), del año 1789, en cuya portada se lee con toda claridad: "Par M. le Chevalier de BouffLers". No podemos asegurar que dicha obra sea de Boufflers; quizás se usó su nombre abusivamente para poder vender la obra mejor. Sin poder concluir sobre su autoría, hemos decidido, sin embargo, señalar aquí su existencia. Presentados como retrato de las costumbres de la época y conjunto de recuerdos personales, estos cuentos recrean la vida sentimental de un joven, sus pasiones y sus aberraciones, y son mostrados al público con una finalidad moral y didáctica.

Cuando Boufflers puso de nuevo los pies en Francia, en 1800, estaba viejo, desgastado, achacoso, desalentado, y era melancólico y aburrido (Uzanne, 1878: LV). Boufflers y su esposa ocupaban, desde su regreso a París, un piso bastante modesto en el que vivían muy humildemente, en rue du Faubourg-Saint-Honoré, $n^{\circ}$ 144. Pudo permitirse además una casita de campo en Saint-Léger, en los alrededores de París, cerca de Saint-Germain, en donde pasaba el verano; allí, se entretenía cuidando de su jardín y escribiendo (Vaget, 1976: 108). Alex Sokalski señala que no siempre debió de ser fácil para Boufflers escribir un cuento, subrayando la afirmación de Jeanine Delpech de que los cuentos que Boufflers publicaba entonces en el Mercure eran trabajos más necesarios que agradables que le permitían a él y su compañera vivir humildemente. En una carta ${ }^{4}$ del 24 de septiembre de 1807 al joven Amaury Duval, entonces redactor jefe del periódico, Boufflers se excusa de no poder enviarle nada:

des affaires et des occupations impérieuses m'ont empêché jusqu'à présent de mettre la main à la plume pour commencer ce petit conte qui est seulement dans ma tête et qui m'en sortira peut-être pas aussi tôt ni aussi heureusement que je le voudrois; car les accouchemens de ce genre ne sont ni plus faciles ni plus sûrs que les autres (citado por Sokalski, 1995: 94).

3. A pesar de que en el título se indica la existencia de dieciséis cuentos, el ejemplar de la Bibliothèque Municipale de Lyon sólo incluye once.

4. Carta publicada por Fernand Baldensperger en Le Pays lorrain, en 1934. 
Durante el mes de octubre de 1807, apareció publicado La Mode en el Mercure de France, en tres episodios repartidos en los números CCCXXV (páginas 55-69), CCCXXVI (páginas 103-115) y CCCXXVII (páginas 152-161), correspondientes al sábado 10 de octubre, sábado 17 de octubre y sábado 24 de octubre respectivamente. Cada uno de los tres episodios lleva al final el nombre del autor: M. DE BOUFFLERS. En 1808, La Mode sería publicado en edición separada y traducido al ruso.

\section{Resumen del cuento y esquema actancial}

Dabon, libertino sólo en apariencia porque está de moda, se casa en segundas nupcias con Hortense, frente a la que aparenta indiferencia porque está de moda, que exhibe como una mujer de moda, acompañada por su aparente amante, una necesidad de la moda: "il se flatta de montrer bientôt une femme de bon air et una maîtresse de bon ton enchaînées à son char de triomphe" (Boufflers, 1995: 215). El despecho que Madame d'Erminy, la falsa amante pero auténtica libertina, concibe por la boda de su esclavo oficial y la envidia que siente ante la belleza y la virtud de Hortense, movilizan en ella todos los recursos de la malicia, del odio y de la corrupción. Ataca primero su belleza, empleando todos sus conocimientos para afearla, aconsejándole maquillajes deliberadamente mal elegidos y vestidos poco favorecedores. Pero la belleza natural y la juventud de Hortense triunfan sobre las artimañas, y lejos de caer en ridículo, recibe numerosos cumplidos. Madame d'Erminy ataca entonces su virtud, que se promete corromper, y, para ello, utiliza a Volzel y a Luzival. Pero la virtud de Hortense resiste a todos. Dabon y Hortense se ven obligados a escapar a una casa en el campo para no caer en las redes de la seducción.

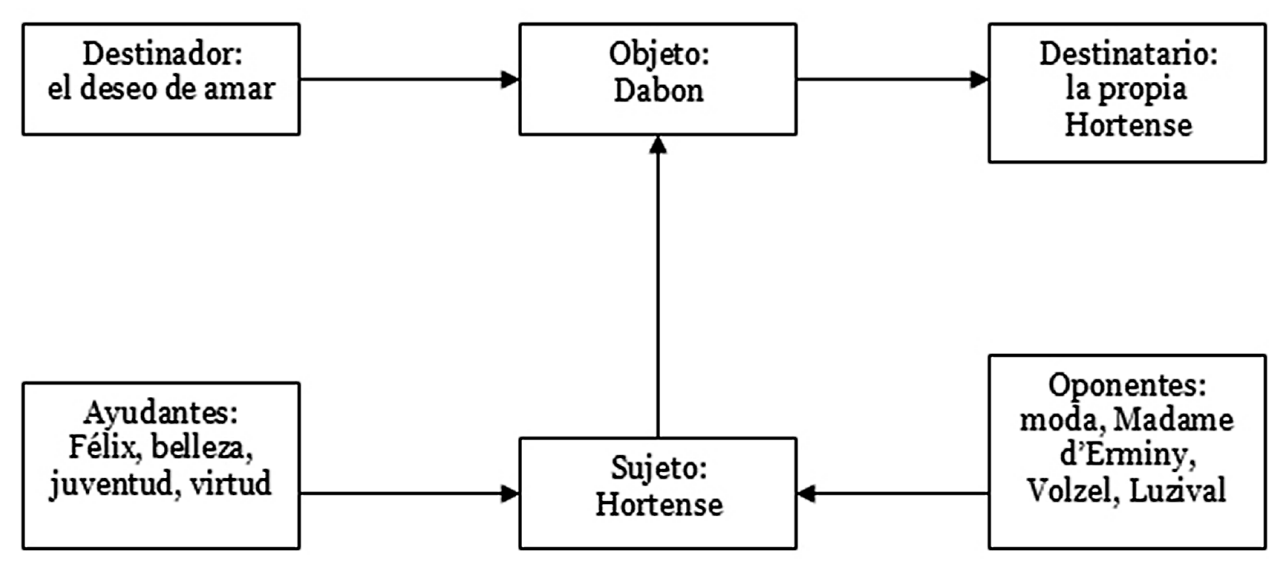


Siguiendo el sistema de Greimas basado en las seis funciones actanciales, encontramos, en el cuento de La Mode, un sujeto, Hortense, y un objeto, Dabon. En un primer momento, la relación entre sujeto y objeto es de disyunción, pues la distancia afectiva entre Hortense y Dabon es considerable: Dabon se casa con Hortense por su dinero y por su belleza, exhibiéndola en los salones como una mujer de moda e ignorándola porque es lo que está de moda. Pero después, sujeto y objeto pasarán de la disyunción a la conjunción, es decir, Dabon se quitará finalmente la venda de los ojos que le impedía ver las virtudes de su joven esposa, y la adorará; por otro lado, Hortense, que siempre había deseado amarlo, lo amará.

El destinador, que va a provocar la acción de Hortense, es el deseo de llegar a amar a un esposo que la ignora. Este deseo hace que Hortense no pierda la esperanza, que se mantenga fiel a su marido, y que cuide al hijo de la primera Madame Dabon como si fuera suyo, dándole al hijo todo el amor que no le puede dar al padre. En este caso, como en todo relato amoroso, el sujeto y el destinatario se confunden, pues el sujeto desea para sí mismo el objeto de su búsqueda.

El principal ayudante, en este cuento de Boufflers, que va a contribuir a que el sujeto (Hortense) llegue a un estado de conjunción con el objeto (Dabon), es Félix, el hijo que Dabon tuvo con su primera esposa, al que Hortense se afana por cuidar y educar con tanto cariño como si se tratara de su propio hijo; es el principal nexo de unión de la pareja. Además, la belleza, la juventud y la virtud de Hortense van a evitar que Madame d'Erminy lleve a cabo su complot con éxito para separar a Dabon de Hortense. En cuanto a los oponentes, los obstáculos con los que Hortense va a encontrarse para conseguir la atención que se merece de su marido, son varios: en primer lugar, la moda, que condiciona por completo la manera de actuar de Dabon, y que le hará ignorar a su esposa y aparentar tener una amante, todo ello para ser admirado por la sociedad; el despecho que Madame d'Erminy concibe por la boda de Dabon y la envidia que siente ante la belleza y la virtud de Hortense, movilizan en ella todos los recursos de la malicia, del odio y de la corrupción; finalmente, Volzel y Luzival, donjuanes hastiados, interesados y cínicos, son los principales instrumentos de Madame d'Erminy, de los cuales se va a valer para intentar conseguir sus oscuros propósitos.

\section{Análisis temático: La corrupción de la sociedad o la lucha del vicio contra la virtud}

Todos los cuentos de Boufflers publicados en la primera década del siglo XIX reflejan el deseo de su autor de retirarse de la sociedad que le decepciona, que ya 
era el tema de su obra maestra de juventud, La Reine de Golconde (1761) (VicenteYagüe, 2012a: 341). "La Mode describe la corrupción que existe en los círculos mundanos de la alta sociedad parisina y que hace imposible toda forma de felicidad a los individuos buenos, sencillos y honrados" (Vicente-Yagüe, 2007: 322). Para él, lo que arruina la mentalidad de la gente y desnaturaliza toda relación entre los miembros de la sociedad, es la obligación tiránica de ajustar sus ideas, sus gustos y sus maneras de actuar a los imperativos de este fenómeno social incontrolable que es la moda. Boufflers comienza su relato con una reflexión sobre las modas, su escasa duración y cómo son capaces de influir sobre cualquier aspecto de nuestra vida.

\begin{abstract}
Si quelque savant voulait entreprendre d'écrire l'histoire de la judicature, on y verrait que depuis l'aéropage jusqu'au dernier bailliage, despuis les amphictions jusqu'aux juges de paix, les hommes n'ont cessé d'ériger et de renverser des tribunaux. Je n'en connais qu'un seul qui soit à l'abri de toutes les révolutions, parce qu'il est lui-même une révolution interminable. C'est sa mobilité qui le soutient. Tout ce qu'il décide, il se presse de le désavouer, et chacune de ses ordonnances n'a d'effet que pour le tems d'en rendre une autre. Ses magistrats sont heureusement dispensés de gravité, de lumières, de vertus. Les femmes y dominent; la jeunesse y préside; l'âge mur y est sur les derniers bancs; la vieillesse y perd sa voix: ce tribunal c'est la mode. [...] elle touche à tout, elle frivolise tout; elle influe, à notre insçu, sur nos sentimens les plus intimes, sur nos plus grands intérêts, les mœurs, les arts, les sciences, la politique même; il faut que tout lui paye un droit, et c'est peu d'égarer telle ou telle mauvaise tête, on l'a vue quelquefois perdre des nations (Boufflers, 1995: 213-214).
\end{abstract}

Boufflers entiende este término en el sentido de la definición de la propia Encyclopédie ${ }^{5}$.

La Mode es, por un lado, un cuento moral que se propone denunciar las fechorías de la moda, que corrompe y tiraniza a los hombres, y, por otro lado, un cuento edificante que demuestra que la virtud puede triunfar en cualquier parte. El autor sabe elegir el momento crucial, un encuentro entre la inocencia y la astucia, para exponer sus ideas. Se trata de la historia, clásica en el siglo XVIII, de la joven

5. "Mode: Ce terme est pris généralement pour toutes inventions, tous usages, introduits dans la société par la fantaisie des hommes. En ce sens, on dit que l'amour entre les époux, le vrai génie, la solide éloquence parmi les savants, cette gravité majestueuse qui, dans les magistrats inspirait tout à la fois le respect et la confiance au bon droit, ne sont plus de mode. On a substitué à celui-là l'indifférence et la légèreté, à ceux-là le bel esprit et les phrases, à cet autre la mignardise et l'afféterie. Ce terme se prend le plus souvent en mauvaise part sans doute, parce que toute invention de cette nature est le fruit du raffinement et d'une présomption impuissante, qui, hors d'état de produire le grand et le beau se tourne du côté du merveilleux et du colifichet" (citado por Vaget, 1976: 158-159). 
pura, bella y virtuosa que, recientemente introducida en la sociedad, lucha contra seres corruptos que persiguen su desdicha. Recién salida de un convento en donde ha pasado su juventud rodeada de libros, leyendo a hurtadillas novelas que hacen volar su imaginación, Hortense es una joven tímida, inocente y muy alegre. Humilde, incauta, inexperta en la vida en sociedad, se hace una idea errónea de las gentes que va conociendo. No es presuntuosa ni desconfiada, por lo que no se imagina que pueda existir maldad.

Hortense, pleine de vertu, d'esprit, de grâces, de bonhomie et d'inexpérience, apportait dans le monde où elle arrivait, de solides principes, des idées fausses et les plus riantes illusions; elle supposait son cœur et son esprit à tout ce qu'elle rencontrait, sans se douter qu'elle fût ni meilleure, ni plus jolie, ni plus aimable que le commun des femmes. Également loin de la défiance et de la vanité, elle était tentée de croire qu'il n'y avait que des Hortenses dans Paris; enfin, comme elle se sentait d'avance disposée à l'amitié, et qu'elle regardait la bienveillance comme le devoir du cœur, notre jeune mariée se figurait qu'elle allait nager dans une mer de délices (Boufflers, 1995: 216-217).

En cuanto a su exterior, nuestra heroína está del mismo modo por encima de todo aquél que la rodea. Bondad y belleza van de la mano en este personaje. Sus gestos, sus andares, su rostro, el sonido de su voz... convierten sus palabras en algo maravilloso, lleno de gracia.

Hortense, la plus belle personne de son tems, avait je ne sais quoi dans son air, dans ses traits, dans sa démarche, qu'on préférait encore à sa figure. Il semblait qu'on aperçut sa bonté avant sa beauté; car l'intérêt précédait l'admiration: et en la voyant, pour la première fois, on aurait cru l'aimer de tout tems (Boufflers, 1995: 217).

Hortense se casa con Dabon, viudo y presumido, habitual de los salones, que la ha desposado por su dote y su belleza. Este héroe masculino es un esclavo de la moda; todas sus decisiones están condicionadas por ella.

M. Dabon était un de ces observateurs obséquieux de la mode, qui croiraient manquer au plus saint des devoirs, s'ils prenaient une détermination sans la consulter. Il s'était marié une première fois, pour avoir tout d'un coup cinquante mille écus de rente; ce qui est un grand moyen d'être un homme à la mode, et en sa qualité d'homme à la mode, il les avait mangées. Comme la mode ne défend pas de se donner un héritier, il eut un enfant de sa femme; mais il n'osa pas aller plus loin, dans le doute si la mode l'y autorisait (Boufflers, 1995: 214). 
Hasta tal punto que su felicidad depende de ésta: "attendant sans doute, pour être heureux dans son intérieur, que la mode le lui permît" (Boufflers, 1995: 215). Pero la primera mujer de Dabon, a la que abandona tras tener un hijo, el pequeño Félix, no se queda atrás:

La dame abandonnée de son mari, n'en mena point une vie plus triste pour cela, parce qu'alors ce n'était point la mode; elle supporta au contraire son malheur, pendant environ cinq ou six ans, avec une gaîté vraiment philosophique; et après une et mille folies, elle mourut à la fin et même à la suite d'un carnaval, parce que c'était la mode (Boufflers, 1995: 214).

Tras la muerte de su primera esposa, Dabon se casa con Hortense, una mujer con dinero, sin importarle nada más de ella, sólo porque esto está de moda.

Comme M. Dabon était un homme de fort bonne maison, il se présenta pour lui un second parti, meilleur encore que le premier; et l'on peut juger par-là que c'était ses ancêtres qu'on épousait plutôt que sa personne. Il vit l'état des biens, ne s'informa point du reste, et, sur le champ, il se remaria, sans trop savoir à qui, mais bien sûr de ne rien faire en cela contre la mode qui approuve, qu'en fait de mariage surtout, on s'en fie au hasard (Boufflers, 1995: 214).

La joven Hortense, ignorada por su marido, no se siente sin embargo desgraciada, pues encuentra una agradable compañía en el hijo de la primera esposa de Dabon, al que entrega todo su cariño y cuida como si se tratara de su propio hijo.

En effet, Hortense s'était attachée, dès le premier jour, à cette aimable petite créature. Bientôt, elle avait brigué la charge de sa gouvernante, et M. Dabon avait donné cet enfant à sa femme, avec autant d'indifférence qu'il aurait donné une poupée à son enfant (Boufflers, 1995: 218).

Hortense es feliz empleando las horas de su día a día en él, sin que otros quehaceres de la vida en sociedad la aparten de ello: "Vous savez combien je préfère la retraite à la société, et à l'exception de quelques amis de ma mère qui ont bien voulu donner des soins à mon enfance, mon savant, mon homme de lettres, mon philosophe, c'est Félix" (Boufflers, 1995: 239-240). Con toda su ilusión, se entrega a su educación. Le enseña a leer, escribir, música, baile, dibujo, pero también lo inicia en la razón, la bondad y la virtud.

Como no está bien visto para un marido amar a su mujer y serle fiel, Dabon se contenta con exhibirla en los salones como un objeto lujoso para pavonearse y para realzar más el esplendor de su reputación de hombre de buen gusto: "il aura 
de tems en tems besoin de paraître avec sa femme pour s'y montrer dans toute sa gloire, et pour exciter ou, à parler plus juste, pour obtenir ce qu'un homme à la mode ambitionne le plus, ... l'envie" (Boufflers, 1995: 251). Pero Dabon, esclavo del qué dirán y partidario servil de los usos vigentes, no es libertino. Su apego público a una de las mujeres más destacadas de París, Madame d’Erminy, "la perle des femmes à la mode" (Boufflers, 1995: 215), es un título del que se vanagloria pero que no corresponde a la realidad. Dabon quiere hacer de su esposa una mujer "à la mode" (Boufflers, 1995: 229).

Aussi M. Dabon aurait-il changé de bon cœur tout le mérite, tout le charme de sa jeune épouse contre les bons airs qu'il espérait lui donner; il attendait, pour en tirer vanité, qu'elle fût une élégante, et le peu de familiarité dont il l'honorait dans son intérieur, il s'en cachait comme un autre mari se cacherait de ses bonnes fortunes; bientôt, même, il ne la vit presque plus que pour lui parler d'affaires, craignant le scandale qu'un trop bon ménage aurait causé à toute sa société (Boufflers, 1995: 217-218).

Presenta en sociedad a la joven Hortense con un peinado y un vestido de moda: "Hortense y parut avec le passe-port des deux plus grandes puissances du tems, une coiffure de Léonard $^{6}$ et un habit de madame Bertin ${ }^{7}$. On juge bien que d'après ces titres, la cour n'eut rien à dire" (Boufflers, 1995: 219-220).

Hortense y Dabon son dos ingenuos y la sociedad va a apresurarse para convertirlos en víctimas. La ingenuidad de ella procede de su inocencia y de su ignorancia de las costumbres. La ingenuidad de él viene de una obcecación causada por esta pasión que le empuja a querer ajustarse, cueste lo que cueste, a estas mismas costumbres: “Ce n'était pas qu'il fût absolument dépourvu d'intelligence; mais il ne l'employait qu'à se mieux tromper; et chez lui, comme chez beaucoup d'autres, l'esprit était au service de la sotisse" (Boufflers, 1995: 215). Dabon tiene muy bien estudiada la estrategia para ser admirado por la sociedad; presenta su mujer a su amante en título con un doble propósito:

Il se faisait une fête de montrer sa femme à sa maîtresse, et sa maîtresse à sa femme; croyant que chacune des deux lui donnerait un relief auprès de l'autre. Car, sans être

6. Léonard-Alexis Antier o Autier, conocido por su nombre de pila, Léonard, peluquero de la reina María Antonieta, fallecido en París en 1820.

7. Marie-Jeanne Rose Bertin (1747-1813), sombrerera y modista de la reina María Antonieta, fue la primera diseñadora francesa célebre a la que se le acreditó abiertamente el haber traído la moda y la alta costura a la palestra pública. 
fort amoureux d'Hortense, il espérait bien en être aimé, et l'amour de la plus jolie femme de Paris, devait lui donner une célébrité de plus. D’un autre côté, madame d'Erminy ne manquerait pas d'en être jalouse, et la jalousie d'une femme à la mode est le plus haut degré d'illustration (Boufflers, 1995: 221).

Y le confía la educación de ésta para que la instruya en la vida en sociedad. La joven esposa, "la victime", "la pauvre Hortense", no se opone y su inocencia le hace ver en Arzélie (Madame d'Erminy) a una amiga. Para ella, es "la femme la plus à la mode".

\begin{abstract}
Aimer, était le seul besoin de son cœur. On avait eu beau lui répéter que toutes les dames se haïssent à plaisir, et que celles qui cessent d'être jolies ont surtout une aversion décidée pour celles qui commencent, son cœur lui disait autre chose. La nature l'avait comme privée de l'organe de la haine, son esprit se refusait même à y croire, et les malveillans lui parassaient quelque chose d'aussi extraordinaire à rencontrer dans la société, que des loups et des tigres dans un jardin (Boufflers, 1995: 222).
\end{abstract}

Madame d'Erminy se dirige a ella como "mon cœur", "ma chère", mientras que a Dabon intentará mostrársela como "un joli petit serpent" o "une petite vipère". Pero bajo estas apariencias de mujer de mundo y de coqueta distinguida, Madame d'Erminy esconde un temperamento vicioso y destructor: "vive, méchante, audacieuse, adroite, hypocrite, elle avait l'art de mettre sur toutes ses actions un nuage qui déroutait toutes les conjectures" (Boufflers, 1995: 225). La primera vez que Madame d'Erminy ve a Hortense, se siente amenazada ante la belleza de la joven: "Elle paraît, et tous les yeux sont éblouis. Au silence de la surprise succède l'accent de l'admiration. Arzélie, entourée d'un essaim d'adorateurs légers, craint qu'à la première vue d'Hortense ils n'aient changé d'idole, et la haine est déjà dans son cœur" (Boufflers, 1995: 222). Todo el mundo ve las virtudes de Hortense, pero temen decir lo que piensan para no ofender a Madame d'Erminy.

La grâce d'Hortense, sa candeur, sa douceur, son maintien, tout ce que ses yeux laissaient entrevoir à travers le voile de la modestie, avait fait son effet, quoique sur des cœurs déjà plus ou moins étrangers à la nature: chacun voudrait au moins avertir Hortense d'un triomphe dont elle n'a pas l'air de se douter; mais un pouvoir magique les enchaînait; c'était celui d'Arzélie. Il n'était permis de louer qu'elle, devant elle; la moindre distraction en faveur de toute autre eût offensé la grande prêtresse, que dis-je? la déesse de la mode (Boufflers, 1995: 224).

El ingenuo Dabon no es capaz de ver las astutas maniobras de Madame d'Erminy. 
Ce bon M. Dabon aurait vu tout cela s'il avait pu voir quelque chose, et le voile n'êtait épais que pour lui. Comme son amour ne marchait qu'à la suite de sa vanité, il se contentait de passer pour l'ammant d'Arzélie, sans l'être. L'honorifique lui suffisait, tandis qu'Arzélie, de son côté, prenait plaisir à tourner tous les soupçons du public sur celui de sa société qui les méritait le moins (Boufflers, 1995: 226).

Y piensa que no puede haber otra justificación para el comportamiento entre su joven esposa y su amante en título que la de los celos recíprocos.

Abandonada por su juventud pero aun halagada y apreciada, Madame d'Erminy conserva su poder sobre los petimetres de los que se rodea, ejerciendo sobre ellos sus talentos de intermediaria diabólica. Temida y adulada, su autoridad es más respetada porque se encuentra, por su nacimiento, en contacto con hombres influyentes de quienes depende la fortuna de estos jóvenes. Coqueta con todo el mundo, acapara la atención de la gente que le rodea y no permite que nadie le haga sombra. Es una mujer malvada, astuta e hipócrita. Todos deben seguirle la corriente: ella es quien marca la moda.

Hors de son temple point de salut; et c'était d'elle que tout agréable devait tenir son brévet d'élégance. L'opinion (à la vérité celle des gens que ne pensent pas, et c'est la majorité), l'avait élévée au grade de Fée, et en cette qualité, aussi bien qu'en celle d'amie régnante d'un ministre en faveur, tout lui était facile, tout lui était permis; l'esprit s'attachait de lui-même à ce qu'elle disait, le charme à ce qu'elle faisait, la vogue à ce qu'elle approuvait, la disgrâce à ce qu'elle critiquait (Boufflers, 1995: 224-225).

Madame d'Erminy pretende enterarse de todo lo que sucede a su alrededor, y no perdona que le oculten nada. Celestina en su propia corte, dirige las operaciones necesarias para llegar a la unión de los jóvenes que se rinden a sus pies, a los cuales maneja como marionetas: "elle nouait ou dénouait à son gré les tendres liens, plaçait, déplaçait, remplaçait les amans et les maîtresses, et faisait de la galanterie une sorte d'agiotage dont elle n'avouait sûrement pas tous les profits" (Boufflers, 1995: 226). Hace creer a los hombres con los que trata que su interés por cada uno de ellos es exclusivo y, sin embargo, los utiliza a todos para sus fines malévolos: son sus esclavos. Por otro lado están Volzel y Luzival, con los que es totalmente franca y puede maquinar abiertamente, pues tienen su confianza.

Tous les deux passés maîtres en fait de bons airs; tous les deux instituteurs en titre des jeunes gens qui aspiraient à la corruption; tous les deux blasés sur tout ce qui tient au sentiment et même au plaisir; tous les deux ne trouvant plus de délices que dans la trahison, et ne jouissant vraiment, quand ils pouvaient parvenir à séduire de 
pauvres femmes, que de l'avant-goût du bonheur de les perdre. Arzélie leur parle, ils l'entendent, et semblables à des démons qu'elle aurait évoqués, ils la quittent pour lui obéir (Boufflers, 1995: 232).

El despecho que Madame d'Erminy concibe por la boda de su esclavo oficial y la envidia que siente ante la belleza y la virtud de Hortense, movilizan en ella todos los recursos de la malicia, del odio y de la corrupción.

Il n'en était pas moins vrai que madame d'Erminy était outrée. Jamais elle n'avait eu un aussi rude assaut à soutenir. Ce mariage lui avait donné de l'humeur, et ce visage ne faisait qu'y ajouter. Cependant comme il faut de la réflexion en toutes choses et surtout dans la méchanceté, elle réfléchit et se dit à elle-même: "Montrer de l'humeur à Dabon, c'est le faire triompher; rompre avec lui, c'est avouer ma honte; non; gardons une dupe et perdons une rivale. Mais surtout cachons nos desseins, et jurons à notre ennemie la haine la plus tendre" (Boufflers, 1995: 228).

Ataca primero su belleza, empleando todos sus conocimientos para afearla, aconsejándole maquillajes deliberadamente mal elegidos y vestidos poco favorecedores.

Tout est choisi, tout est placé de main de maître, mais de maître dans le grand art de nuire; les couleurs, les plus propres à tuer le teint; des fleurs jaunes dans des cheveux blonds comme de la soie, du rouge de brune qu'on dit être le poison des blondes; une robe craimoisie qui traîne d'un côté, qui relève de l'autre sur un corset lacé de manière à rendre, s'il se peut, la taille suspecte, et par-dessus tout cela un fichu qu'on n'accusera pas de trop de complaisance pour des regards indiscrets (Boufflers, 1995: 232-233).

Pero la belleza natural y la juventud de Hortense triunfan sobre las artimañas, y lejos de caer en ridículo, recibe numerosos cumplidos.

Elle marche, et l'on ne prend pas garde à celles qui dansent; elle danse, mais comme si elle avait appris à danser du premier maître d'Herculanum ${ }^{8}$; c'est une grâce, une facilité, une correction, une mesure, une gaîté, une décence... Pas un pas, pas un mouvement, pas un air de tête qui ne donne le besoin d'applaudir. On quitte tout, on accourt, on se presse, on se demande est-ce une femme? est-ce une Nymphe? est-ce

8. Herculano, antigua ciudad romana de la región de Campania, hoy en ruinas, que en su día fue más pequeña y más rica que Pompeya. Hoy es conocida por haberse conservado, junto con Pompeya, debido al hecho de haber sido enterrada en las cenizas de la erupción del Vesubio el 24 de agosto del año 79 . 
une Déesse? et cette pauvre madame d'Erminy qui voit, qui entend tout cela, qui enrage d'avoir donné son bal, et qui est là comme Vénus au triomphe de Psyché ${ }^{9}$ (Boufflers, 1995: 233-234).

Arzélie ataca entonces su virtud, que se promete corromper, y, para ello, utiliza a Volzel y a Luzival. Éstos son tanto más peligrosos cuanto que la conquista de la "charmante Hortense" representa un desafío a su reputación y cuanto que nunca retroceden ante ningún medio deshonesto, como la violación y el chantaje. Pero la virtud de Hortense resiste a todos.

Dabon está tan ciego que seguirá defendiendo a Madame d'Erminy incluso después de que, en un maniobra dirigida por ésta, uno de sus cómplices acose a Hortense: “Je n'aurais jamais conçu qu'Arzélie pût manquer un instant au bon goût, ni au bon ton. Mais elle voulait vous corriger de vos enfances et vous montrer la différence du monde, à votre couvent" (Boufflers, 1995: 248). La adhesión de Dabon a la moda le llevará incluso a reprochar a su joven esposa su devoción por la virtud, pues no es algo que esté bien visto en la vida en sociedad: "sachez que ce mot de vertu, qui est la plus belle chose du monde dans les romans, n'a aucun succès dans la société. Entendez-vous un homme, une femme à la mode prononcer le mot de vertu?" (Boufflers, 1995: 248). Dabon se burla de ella, pues parece vivir dentro de una novela, y no le permite retirarse al campo y alejarse de la sociedad, que es lo que ella desea.

vous ne rêvez que vieux châteaux, de la construction de madame Radcliff ${ }^{10}$, avec escarpes, contr'escarpes, fossés, tours, machicoulis, trappes, grilles, etc., etc. Vous aurez à vous représenter au milieu de tout cela, jeune femme, bien belle, bien tendre, bien mélancolique, instruisant un jeune enfant dont elle n'est pas la mère, mais qui lui rappelle les traits de son persécuteur. Voilà de la matière pour beaucoup de chapîtres; voilà de quoi nourrir une âme sensible; tenez; j'ai votre secret (Boufflers, 1995: 249).

Madame d'Erminy aprovechará la actitud de Dabon, a quien llamará "mon pauvre Dabon", para dar a Hortense viles consejos e intentar ponerla en su contra.

Jugez-en par vous-même, disait la méchante à la bonne (avec cet air d'affection qui sert si bien à la haine) tout ce que vous faites pour vous attacher votre mari, le

9. Boufflers piensa sin duda en la larga serie de pruebas impuestas por Afrodita a Psique, de las que sale victoriosa gracias a la ayuda de Eros.

10. Ann Ward Radcliffe (1764-1823), novelista británica, pionera de la llamada novela gótica. 
détache; il me semble voir un enfant tirer sur un nœud coulant et le défaire, en essayant de le serrer. Ces hommes-là ne sont pas ce que vous croyez; ils ne pèsent pas les choses dans la balance de la justice, mais dans celle de l'opinion; ce n'est pas le mérite qu'il leur faut, c'est la vogue; et croyez-moi, l'inquiétude même que nos succès leur donnent ne nous nuit pas. Mais vous, ma chère, avec votre modestie, votre pureté, votre amour de la retraite, votre bonté céleste, vos soins plus que maternels pour un enfant dont vous n'êtes que la belle-mère, vous êtes assurément une belle âme devant Dieu, mais vous pourriez bien n'être qu'une Sœur grise ${ }^{11}$ devant votre mari: les gens de bon air, comme lui, veulent moins nous posséder que nous montrer, moins jouir que se parer de nous; ce n'est pas un trésor qu'ils pensent avoir dans une aimable femme, c'est un diamant, et il faut encore que ce diamantlà ait un brillant entourage (Boufflers, 1995: 250).

Pero Dabon será cada vez más consciente de las virtudes de su joven esposa, la cual despierta gran admiración entre la sociedad, y se conmoverá viendo cómo cuida de su hijo: "D'une part il jouissait avec un peu d'orgueil des succès qu'elle avait dans le monde et dont il s'atribuait tout l'honneur; de l'autre, il était de jour en jour plus touché des soins charmans qu'elle donnait à Félix, toujours plus persuadé que ce ne pouvait être que le père qu'on aimait dans l'enfant" (Boufflers, 1995: 252). Sin embargo, será víctima del complot creado contra ella y por un instante la creerá infiel: "Il entre chez lui furieux, fait une scène horrible à la pauvre Hortense qui ne sait pas même sur quoi” (Boufflers, 1995: 259). Maquinación que finalmente será destapada. Podrá quitarse así la venda de los ojos que le impedía ver a su joven esposa tal y como es, y por fin ser feliz el uno junto al otro.

Le masque était tombé. M. Dabon [...] n'avait besoin que d'une forte secousse pour sortir de son ivresse et se réveiller honnête homme. Il rougit d'abord, il rit après de tant d'illusions, ses yeux une fois dessillés, virent enfin sa femme comme elle était, et il l'adora. De son côté, Hortense qui avait toujours désiré l'aimer, l'aima (Boufflers, 1995: 260).

Por otro lado, Madame d'Erminy pagará por sus actos, al igual que sus cómplices Volzel y Luzival, y dejará así de ser una mujer de moda.

une femme à la mode finit bientôt comme la mode elle-même, et passe de mode. [...] Les succès d'Arzélie allèrent toujours en diminuant et sa malice toujours en augmentant, en sorte que la Déesse ne tarda pas à être changée en furie; et il y a tout

11. La Congregación de las Hermanas de la Caridad de Montreal, mejor conocida con el nombre de "Hermanas Grises", nace en 1737. 
lieu d'espérer que les furies ne sont pas heureuses. Il en sera sans doute à peu près de même de Volzel et de Luzival, qui auront trouvé tôt ou tard le prix de leurs noirceurs (Boufflers, 1995: 260).

Este cuento recuerda a los personajes y la intriga de Les Liaisons dangereuses (1782) de Laclos. Ambos relatos ilustran la lucha del vicio contra la virtud. Madame d'Erminy y Madame de Merteuil son mujeres devoradas por una sed desenfrenada de poder; malvadas, hipócritas y celosas, no toleran ninguna rivalidad y se complacen en sembrar el mal. Volzel y Luzival son, como Valmont, esclavos de su vanidad y su única pasión es satisfacerla. Su cinismo y su gusto por el vicio los ayudan privándoles de todo escrúpulo.

En este cuento, Boufflers quiere demostrar que, en la sociedad que él frecuenta, la felicidad es imposible para los seres sensibles y virtuosos, pues el amor y la amistad, únicas fuentes de felicidad, son degradadas. La amistad hace sitio al interés, a la envidia y al odio. El amor conyugal, juzgado ridículo, es remplazado por la galantería y la coquetería, que son juegos estériles y egoístas. En cuanto al amor filial, no queda lugar para él. El único medio de escapar a la tiranía que regula esta sociedad y de resistir al malestar, es el retiro. Éste consiste en abandonar el lugar e ir a vivir, como los héroes del cuento, a una casa en el campo, en medio de la naturaleza y de las gentes sencillas,

Leur parti fut bientôt pris, et tous les deux fatigués, le mari de ses erreurs, la femme de ses triomphes, s'en allèrent avec Félix, leur bienfaiteur commun, dans ce beau château d'Auvergne où l'aimable Hortense avait eu l'envie de cacher ses chagrins et ses charmes. C'est là que tous les deux font la comparaison de ce que la nature donne avec ce que la société promet, et là, contens l'un de l'autre, oubliant le monde, oubliés du monde, heureux par la paix qu'ils trouvent, par les occupations qu'ils s'imposent et surtout par le bien qu'ils font, ils attendent pour revenir à Paris que la raison, la décence, la bonhomie et la morale y soient une fois à la mode (Boufflers, 1995: 260).

o en crearse un mundo aparte, como los filósofos o los hombres de letras. Esta última solución es la que elige Boufflers.

\section{Bibliografía}

BOUFFLERS (1789). Anecdotes amoureuses d'un jeune homme de condition, ou L’Exemple et les passions, divisé en 16 contes. París: Delalain. 
BOUFFLERS (1878). Contes du chevalier de Boufflers. Precedidos de una reseña sobre la vida y las obras de Boufflers por Octave Uzanne. París: A. Quantin.

BOUFFLERS (1995). Contes. Introducción y notas de Alex Sokalski. París: Société des Textes Français Modernes.

CROZE, P. de (1894). Le Chevalier de Boufflers et la comtesse de Sabran, 17881792. París: Calmann-Lévy.

MAUGRAS, G. (1907). La Marquise de Boufflers et son fils le chevalier de Boufflers. París: Plon.

SOKALSKI, A. (1995). "Repères biographiques", "Jugements et portraits", "Introduction", “Appendice”, en Boufflers, Contes. París: Société des Textes Français Modernes, 5-30, 31-51, 53-112, 603-612.

UZANNE, O. (1878). "Notice sur la vie et les œuvres de Boufflers", en Boufflers, Contes du Chevalier de Boufflers. París: A. Quantin, I-LXXIV.

VAGET GRANGEAT, N. (1976). Le chevalier de Boufflers et son temps: étude d'un échec. París: Nizet.

VICENTE-YAGÜE JARA, A. J. de (2007). "Los cuentos del caballero de Boufflers en el siglo XIX”. Anales de Filología Francesa 15: 321-334.

VICENTE-YAGÜE JARA, A. J. de (2008). "L'oeuvre de charité, nouvelle espagnole (1808) de Boufflers". Anales de Filología Francesa 16: 223-238.

VICENTE-YAGÜE JARA, A. J. de (2012a). "El caballero de Boufflers y su sueño de huida social a través de L'heureux accident, conte (1807) y Ah! si..., nouvelle allemande (1810)". Çedille, revista de estudios franceses 8: 331-360.

VICENTE-YAGÜE JARA, A. J. de (2012b). "El viaje del caballero de Boufflers a Senegal y su correspondencia con Éléonore de Sabran”. Estudios Románicos 21: 153-164. 